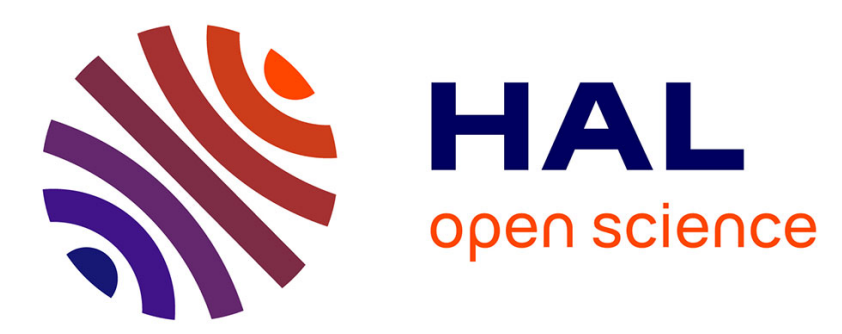

\title{
An expert diagnosis system for the benchmarking of SMEs' performance
}

Sylvain Delisle, Josée St-Pierre

\section{To cite this version:}

Sylvain Delisle, Josée St-Pierre. An expert diagnosis system for the benchmarking of SMEs' performance. 1st International Conference on Performance Measures, Benchmarking and Best Practices in New Economy, 2003, Lisbonne, Portugal. hal-01704920

\section{HAL Id: hal-01704920 \\ https://hal.science/hal-01704920}

Submitted on 8 Feb 2018

HAL is a multi-disciplinary open access archive for the deposit and dissemination of scientific research documents, whether they are published or not. The documents may come from teaching and research institutions in France or abroad, or from public or private research centers.
L'archive ouverte pluridisciplinaire HAL, est destinée au dépôt et à la diffusion de documents scientifiques de niveau recherche, publiés ou non, émanant des établissements d'enseignement et de recherche français ou étrangers, des laboratoires publics ou privés. 
Communication présentée 1st International Conference on Performance Measures, Benchmarking and Best Practices in New Economy, Lisbonne, Portugal - 2003

Business Excellence '03

An Expert Diagnosis System for SMEs

Delisle \& St-Pierre

\title{
AN EXPERT DIAGNOSIS SYSTEM FOR THE BENCHMARKING OF SMES' PERFORMANCE
}

\author{
${ }^{*}$ Sylvain Delisle ${ }^{1} \&$ Josée St-Pierre ${ }^{2}$ \\ Institut de recherche sur les PME \\ Laboratoire de recherche sur la performance des entreprises \\ Université du Québec à Trois Rivières \\ 1 : professor, Département de mathématiques et d'informatique \\ 2 : professor, Département des sciences de la gestion \\ C.P. 500, Trois-Rivières, Québec, Canada, G9A 5H7 \\ Phone : 1-819-376-5011+3832 \\ Fax : 1-819-376-5185 \\ Email : sylvain_delisle@uqtr.ca ; josee.st-pierre@dr.cgocable.ca \\ Web : www.uqtr.ca/\{ delisle, dsge\}
}

\begin{abstract}
Although benchmarking has proven to be valuable for large businesses and organizations for quite sometime, up until recently, serious doubts existed as to its usefulness for smaller businesses. In this paper, we present the $P D G^{\circledR}$, a benchmarking system meant to evaluate SMEs from an external perspective in order to produce a diagnosis of their performance and potential, complemented with relevant recommendations. Our research results show that benchmarking allows SMEs to improve their operational performance thus confirming the usefulness of benchmarking. These results also confirm the value of the recommendations included in the $P D G^{\circledR}$ report concerning short-term actions to be undertaken to modify management practices. We think the $P D G^{\circledR}$ system proves that if the benchmarking approach is tailored to SMEs' characteristics, an adequate tool can be devised and used to help SMEs increase their performance.
\end{abstract}

Keywords: Benchmarking, Performance, Expert Systems.

\section{BENCHMARKING FOR SMES}

The importance of evaluating performance is obvious for business enterprises in general, and for SMEs in particular. Facing increased competitive pressure due to globalization, as well as increased quality and service requirements from their customers, small and medium-sized manufacturers must increase their productivity and their competitiveness in order to survive and prosper, even if they do not intend to become "world class" enterprises. One approach to the evaluation of a SME's situation is to compare the firm's business practices and performance with those of a group of similar firms, that is, to "benchmark" the organization. As management challenges have increased in complexity, benchmarking has become a strategic tool for organizations of all sizes.

Whatever the type of benchmarking used, internal, competitive or generic, it is deemed to be a strategic tool that allows the firm to identify possible sources of improvement in order to increase its performance and its competitiveness
(Haughton et al., 1999). The benefits of benchmarking are being more and more recognized, less so in SMEs however where its use still remains relatively sparse (Prabhu et al., 2000). In this last regard, Monkhouse (1995) states that smaller firms would have a lot to gain by this activity, notably in breaking the entrepreneurs' "isolation" by providing them with information on what is being done by other firms similar to their own. This author notes however that it is very important to first convince entrepreneurs of the relevance and usefulness of such a management tool, thus justifying the significant amount of time spent by themselves and their key employees on benchmarking activities.

Our answer to this challenge of the utmost importance for SMEs was to design, develop and test an advanced computerized benchmarking tool. This tool, the $\mathrm{PDG}^{\circledR}$ (Performance, Development, Growth) system, constitutes the foundation of our work on SMEs benchmarking, a domain in which the LaRePE lab has been involved for many years. This is what we discuss in this paper, taking as the basis of our presentation the $P D G^{\circledR}$ system (www.pdg-sme.ca). 


\section{THE PDG ${ }^{\circledR}$ BENCHMARKING SYSTEM: A BIRD'S EYE VIEW}

The current version of the $\mathrm{PDG}^{\circledR}$ benchmarking system is the result of a long and demanding development process, a project that has been going on for more than 6 years and has so far necessitated a budget of more than 2 million $\mathrm{Ca}$ nadian dollars from multiple funding sources. Many people were involved, all of them in various specialization fields (i.e. management, marketing, accounting, finance, human resources, engineering, innovation, information technology, etc.): researchers, graduate students, research professionals and, of course, SME entrepreneurs.

The goal of the $\mathrm{PDG}^{\circledR}$ system is to evaluate a $S M E$, from an external perspective and on a comparative basis, in order to produce a diagnosis of its performance and potential, complemented with relevant recommendations. Right from the beginning, the project evolved around the concept of a questionnaire that would be used to collect relevant information items on the SME to be evaluated. Data extracted from the questionnaire is computerized and fed into a complex benchmarking system that carries out the evaluation. The latter is performed in approximately 3 minutes by contrasting a particular SME with an appropriate group of SMEs for which we have already collected relevant data. The PDG ${ }^{\circledR}$, s output, which we call the $P D G^{\circledR}$ report, or report in Figure 1 below, is a detailed report in which 28 management practices (concerning human resources management, production systems and organization, market development activities, accounting, finance and control tools, effectiveness and vulnerability), 20 results indicators and 22 general information items are evaluated, leading to 14 recommendations on short term actions the evaluated SME could undertake to improve its overall performance. The $\mathrm{PDG}^{\circledR}$ system is fully implemented and the actual version has been in production for 2 years. So far, we have produced more than 600 reports and accumulated in the $\mathrm{PDG}^{\circledR}$, $s$ database the evaluation results of 400 different manufacturing SMEs.

Figure 1 below shows the $P D G^{\circledR}$ as a black box system, connected to an Oracle database that collects all the relevant data for benchmarking purposes. A team of multidisciplinary human experts constantly monitors the $P D G^{\circledR}$ reports in order to ensure the evaluation is accurate and the recommendations are relevant. This validation phase, which always takes place before the report is sent out to the evaluated SME, is an opportunity to make further improvements to the $\mathrm{PDG}^{\circledR}$ system, whenever appropriate. It is also a valuable means for the human experts to update their own expertise on SMEs. Figure 1 also shows that an intermediary partner is part of the process in order to guarantee confidentiality: nobody in our lab knows to what companies the data are associated.

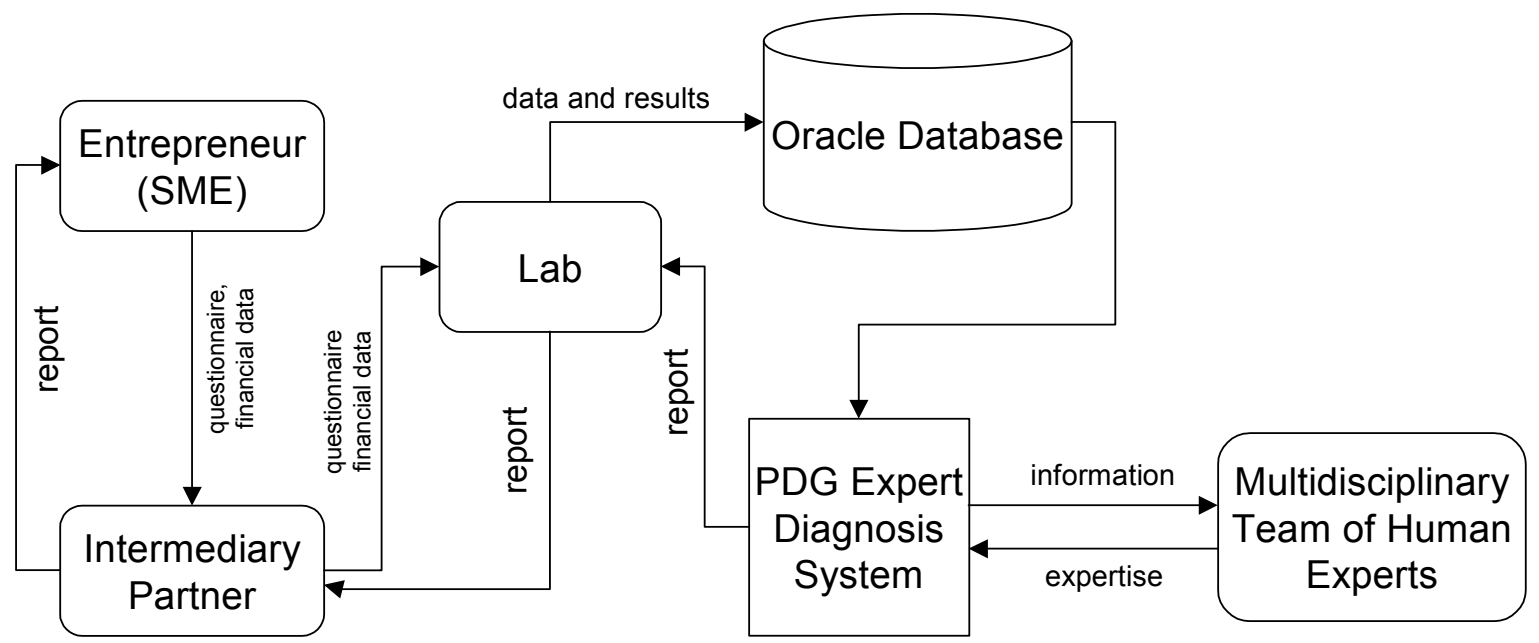

Fig. 1. The $P D G^{\circledR}$ system: evaluation of SMEs, from an external perspective and on a comparative basis, in order to produce a diagnosis of their performance and potential.

A good deal of multi-domain expertise and informal knowledge engineering was invested into the design of the $\mathrm{PDG}^{\circledR}$ s extended questionnaire, as well as into the benchmarking system. In fact, at the early stage of the project, it was even hoped that an expert-system approach would apply naturally to the task we were facing-a prototype expert system was developed for a subset of the $P D G^{\circledR}$ dealing only with human resources. However, reality turned out to be much more difficult than anticipated. In particular, the knowledge acquisition and knowledge modelling phases (Turban \& Aronson, 2001; 
Sierra-Alonso, 2000) were very demanding, especially in the context of a multidisciplinary domain such as that of SME benchmarking.

The current version of the $\mathrm{PDG}^{\circledR}$ system, although not implemented with artificial intelligence techniques, e.g. knowledge base of rules and facts, inference engine, etc. (see, e.g., Santos et al. 2002), qualifies as a "black-box" expert system. The expertise hidden in the $\mathrm{PDG}^{\circledR}$ system comes from human experts that have identified the appropriate contents, selected relevant information, associated adequate relative weights to evaluation elements, and prepared suitable recommendations for the evaluated SME. The knowledge, information and algorithms it uses allow it to produce outputs that only a human expert, or in fact several human experts in different domains, would be able to produce in terms of diagnosis quality, including recommendations. Over $90 \%$ of the reports produced by the $\mathrm{PDG}^{\circledR}$ system need no modification whatsoever before being returned to the evaluated SME. These reports contain mostly coloured diagrams and simple explanations that are formulated in plain
English (or French) so that SME entrepreneurs can easily understand and interpret them.

\section{TAKING A CLOSER LOOK AT THE PDG ${ }^{\circledR}$ 'S MAIN COMPONENTS}

If we look at the $\mathrm{PDG}^{\circledR}$ from a systemic viewpoint, as illustrated below in Figure 2, we see that:

- Input consists of a broad-coverage questionnaire filled by the SME, their financial statements, including the accompanying notes, of the last 5 years;

- Processing is performed by the expert diagnosis system;

- Output consists of a detailed benchmarking evaluation of the SME's performance, plus recommendations.

In this section, we will take a look at these three main components in order to better understand the PDG ${ }^{\circledR}$ system and how it works.

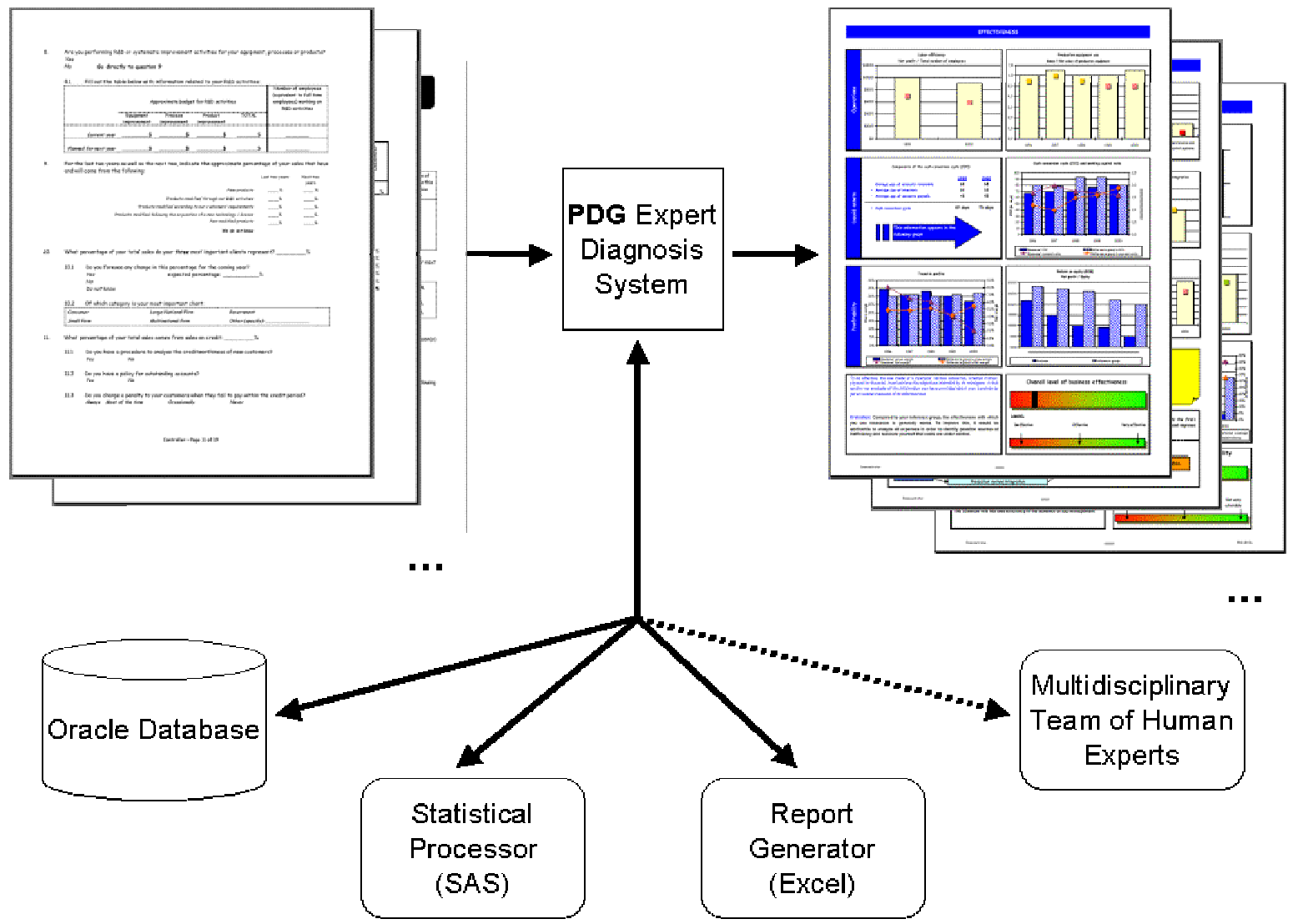

Fig. 2. A simplified view of the $P D G^{\circledR}$ system and its main components: from a broad-coverage questionnaire and financial statements to a detailed benchmarking evaluation and associated recommendations. 


\subsection{The PDG ${ }^{\circledR,}$ ' Input: the SME's Data}

The questionnaire on which is collected the data from the manufacturing SME to be evaluated is broad although not deeply specialized in any of the business' functions. It consists of 19 pages (plus a one-page appendix of term definitions) organized in these main sections:

- An indication of the SME's preference as to what reference group it wishes to be compared to. This information is crucial for benchmarking purposes. It is our experience that SMEs often have a hard time identifying their reference group, especially the first time around. This is one area where human expertise is needed: an expert of our lab must approve the group selection before proceeding to the evaluation itself-see the beginning of section 3.2

- A section to be filled by the business owner-manager: it includes questions about the owner's background, the existence of a board of directors, the strategy regarding new technologies, the strategy on market development, the usual sources of information on a dozen of subjects, the existence of a designated person in charge in various services or departments, an opinion on the firm's positioning relative to its competitors, a forecast on the firm's financial situation, and so on.

- A section to be filled by the human resources manager: it includes questions about the number of employees in various categories, employee training, employee evaluation, sharing of information in the organization, a forecast on the evolution of several employee categories, and so on.

- A section to be filled by the controller or the general manager: it includes questions about the enterprise's ownership, its main products or services, the geographical sales distribution, collaborations or alliances with other organizations, the value of production equipment, research and development, the importance of sales on credit, dependence on principal clients and suppliers, accounting and financial tools, information technologies, credit, interest rate, and so on.

- A section to be filled by the production manager: it includes questions about the nature of the enterprise's manufacturing operations, the usage of equipment over the year, subcontracting, certification, standards, continuous improvement ac- tivities, quality, safety, use and proficiency in the use of various equipments and technologies, integration of production systems, control of operating costs, and so on.

Once all the data on a questionnaire, plus the complete financial statements of the last 5 years, have been manually verified, they are typed in via a software dedicated to this task and will finally end up in the $P D G^{\circledR}$ 's database, ready for benchmarking. It is worth mentioning that the questionnaire's data complexity and diversity (i.e. qualitative, quantitative, historical, conjectural, perceptual, etc.) must be matched by the expert diagnosis processor that must contain all the required information and encoded knowledge to correctly perform the evaluation.

\subsection{The PDG ${ }^{\circledR,}$ s Central Processing: Expert Diagnostic}

The heart of the expert diagnosis system can be best described in relation to the report generator component, which acts as the main program. The 8 main steps of processing are:

1. The reference group is created according to a number of criteria usually after several iterations. It is sometimes necessary to create a few tentative reference groups in order to select the most appropriate one, thus ensuring the statistical validity of the benchmarking results, while preserving confidentiality of all SMEs. This processing takes place within the Oracle database.

2. A number of statistical computations (averages, medians, distributions) related to the reference group are performed within the SAS statistical package, after data from the Oracle database has been fetched.

Starting from here, the remaining processing is essentially performed from a Microsoft Excel application:

3. Statistical data is passed from SAS to Excel via an ODBC connection.

4. A bunch of automatic, numerical Excel computations take place at this stage in order to define the relative positioning of the evaluated SME to its reference group. This relative positioning will then be used to define the appropriate graphical representations (including colours), as well as related comments and recommendations.

5. Graphics and various representations associated with the numerical values just computed are then produced. 
6. Textual comments on practices and results are computed, in correlation with the computations completed in the previous steps.

7. An evaluation summary, to appear on the report's first page, is produced. For each of the seven main business functions, it presents a synoptic bar diagram showing the evaluated SME's relative position, plus two recommendations as to what actions should be considered in the next few years.

8. The actual $P D G^{\circledR}$ output report, containing the benchmarking results, is then produced and saved on disk. The report is displayed on the screen by the Excel application.

Step 6 deserves further explanations. In fact, why bother with textual comments to be added to the already abundant information present in the report? The main goal of the $\mathrm{PDG}^{\circledR}$ report is to guide entrepreneurs in the identification of potential sources of improvement in their business' performance. It turns out that the average entrepreneur cannot easily grasp all the information involved in such a report based solely on graphical representations (e.g. charts). This information is thus analysed by the $P D G^{\circledR}$ system and textual comments on practices and results are automatically produced to facilitate the entrepreneur's interpretation task when reading the report.

The actual mechanisms used to automatically produce these textual comments are a bit tricky. In brief, they are similar to early Al techniques devised for natural language processing based on templates. A prototypical comment contains fixed and variable segments. The latter are determined according to the specific numerical values computed for the evaluated SME (during previous steps). Full computational detail on how the $\mathrm{PDG}^{\circledR}$ system produces its results is clearly beyond the scope of the present paper.

\subsection{The PDG ${ }^{\circledR}$ s Output: Benchmarking Results and Recommendations}

The diagnosis produced by the PDG ${ }^{\circledR}$ system through benchmarking is presented in an easy-to-read report that uses mostly graphics, coloured (colours translates into shades of grey here) diagrams and charts, and numerical results-typical SME entrepreneurs are not fond of long textual reports. See the top right corner of Figure 2 for the report's general appearance.

The report consists of 10 pages. The first page presents a summary of the evaluated SME along the main enterprise functions, using a cursor-based graphical representation. The report's next two pages present a summary of the SME's reference group characteristics, all illustrated with coloured pie charts and bar charts. Then a one-page summary on each of the following topic is presented: human resources, production systems, production management, sales/marketing, management and control, effectiveness, and vulnerability. All are illustrated with graphical representations of the kind shown in Figure 3 below. On each of these pages appear brief textual comments and recommendations, when appropriate, on the SME's practices and results. Here is an example comment on practice evaluation of human resources (the variable segment is in italics): "Your human resources management practices are generally more advanced than those of your reference group. You could improve your performance, in particular by implementing participative management to involve employees in the growth of the business." And here is an example comment on human resources results (the variable segment is in italics): "Your overall effectiveness at managing human resources is comparable to that of your reference group. You should pay attention to why certain managerial jobs have a high rate of voluntary departure, with the objective of lowering hiring and training costs."
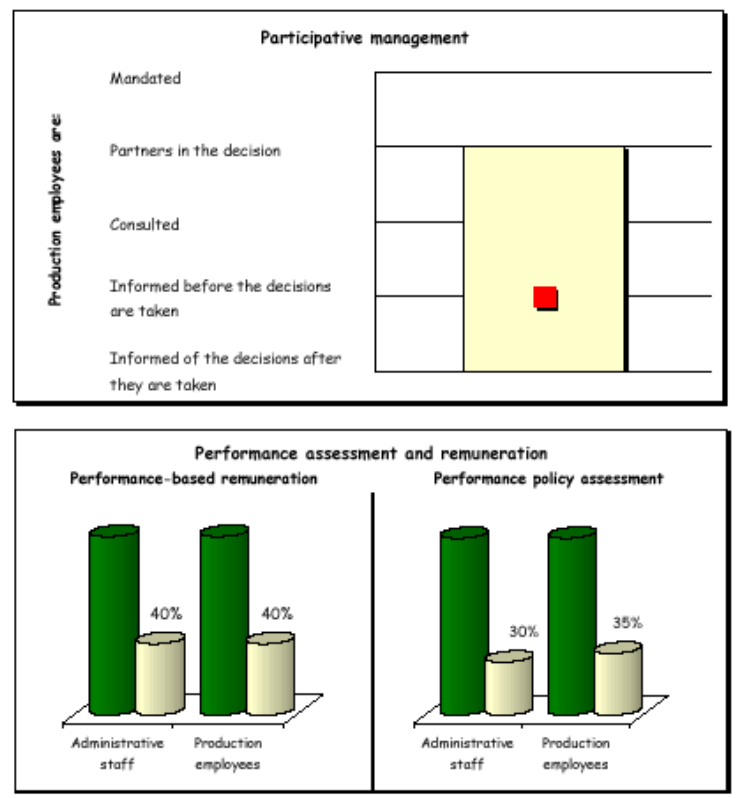

Fig. 3. Graphical representations make benchmarking results easy to understand by always positioning the evaluated SME relative to its reference group.

One final remark on the $P D G^{\circledR}$ report. Before it is sent to the evaluated SME, at least one expert from our lab validates its contents. This expert must complete the comments appearing on the first page by selecting the most appropriate comments from a precompiled list of potentially 
relevant candidates. These textual comments must be determined from a global perspective in which the human expert will consider interrelationships between various aspects that appear independently in the report.

\section{EVALUATING THE USEFULNESS OF THE SYSTEM'S RECOMMENDATIONS}

A study was made of 307 Canadian manufacturing SMEs that have used the $\mathrm{PDG}^{\circledR}$ report, including 49 that have done so more than once. The aim of that study was to show the importance of benchmarking for manufacturing SMEs in the new business environment and to assess the utility of the $P D G^{\circledR}$ report (and, implicitly, of the PDG ${ }^{\circledR}$ system) to help businesses to identify management practices that needed to be adjusted. Our results show that this activity allows these organisations to improve their operational performance confirming the usefulness of benchmarking but also, the value of the recommendations included in the $P D G^{\circledR}$ report concerning short-term actions to be undertaken to modify management practices (St-Pierre, Raymond \& Andriambeloson, 2002). Although benchmarking has proven to be valuable for large businesses and organizations for quite sometime, up until recently, serious doubts existed as to its usefulness for smaller businesses. We think the $P D G^{\circledR}$ proves that if the benchmarking approach is tailored to SMEs' characteristics, an adequate tool can be devised and used to help SMEs increase their performance. Benchmarking allows entrepreneurs to break the isolation in which they may be caught by comparing and positioning their SME to others (Monkhouse, 1995).

\section{CURRENT STATE AND FUTURE DEVELOPMENTS}

The current version of the $P D G^{\circledR}$ system is fully functional and operates on an Oracle database. It also uses the SAS statistics package, plus Microsoft Excel for various calculations and the generation of the final output report. Up until now, SMEs evaluated with the $\mathrm{PDG}^{\circledR}$ were mostly manufacturing enterprises from the province of Quebec (Canada). Other SMEs are from the province of Ontario (Canada) and the USA. Recently, a deal was signed with a French businesspersons group for the production of 100 $\mathrm{PDG}^{\circledR}$ reports per year. Due to important differences between Europe and North America in the presentation of financial information, not mentioning cultural aspects that may have an impact on certain elements, this agreement will necessitate some adjustments to the $\mathrm{PDG}^{\circledR}$ production system.

As far as future developments are concerned, we are conducting an in-depth revision of the current $\mathrm{PDG}^{\circledR}$ system in order to reengineer the system's architecture from a data mining perspective. We also need to migrate to newer and more efficient Web-based technologies (Java and Oracle), thus allowing various improvements and making a further step toward a fully interactive online version of the $P D G^{\circledR}$ system. These developments are also made in response to international potential partners who want to have online access to the $P D G^{\circledR}$ benchmarking system, especially its report, thus reducing the risks of losing strategic and financial information that must be sent by non-electronic mail otherwise.

\section{Acknowledgements}

The authors thank the Groupement des chefs d'entreprise du Québec for their contribution to the PDG project. The authors are members of the Chaire de recherche du Canada sur la performance des entreprises and they would like to thank the Canada Research Chairs Program, the Canada Foundation for Innovation, and Canada Economic Development for their financial support of this research.

\section{References}

Haughton M., Grenoble W., Thomchick E. and Young R. "The Role of Benchmarking in the Performance of the Import Process", International Journal of Physical Distribution \& Logistics Management, Vol. 29, No 9, pp.511-568, 1999.

Monkhouse E. "The Role of Competitive Benchmarking in Small to Medium Sized Enterprises", Benchmarking, Vol. 2, No 4, pp.4150, 1995.

Prabhu V., Yarrow D. and Gordon-Hart G. "Best Practice and Performance within Northeast Manufacturing", Total Quality Management, Vol. 11, No 1, pp.113-122, 2000.

Santos J., Vale Z. and Ramos C. "On the Verification of an Expert System: Practical Issues", Lecture Notes in Artificial Intelligence \#2358, pp.414-424, Springer-Verlag, 2002.

Sierra-Alonso A. "Definition of a General Conceptualization Method for the Expert Knowledge", Lecture Notes in Artificial Intelligence \#1793, pp.458-469, Springer-Verlag, 2000.

St-Pierre J., Raymond L. and Andriambeloson E. "Performance Effects of the Adoption of Benchmarking and Best Practices in Manufacturing SMEs", Small Business and Enterprise Development Conference, The University of Nottingham, 2002.

Turban E. and Aronson J.E. Decision Support Systems and Intelligent Systems, Prentice Hall, 2001. 